\title{
CIGARETTE SMOKING AND FOOD AND NUTRIENT INTAKES IN RELATION TO CORONARY HEART DISEASE
}

R. L. THOMPSON*, B. M. MARGETTS $†$, D. A. WOOD* AND A. A. JACKSON†

* Preventive Cardiology, Medicine 1, University of Southampton, Royal South Hants Hospital, Southampton SO9 4PE

$\dagger$ Institute of Human Nutrition, University of Southampton, Southampton SO9 3TU

\section{CONTENTS}

INTRODUCTION . . . . . . . . . . . . . . . . . . 132

PROBLEMS ASSOCIATED WITH THE INTERPRETATION OF STUDIES 132

DEFINITION OF SMOKING . . . . . . . . . . . . . 132

DIETARY SURVEY METHODOLOGY . . . . . . . . . . . . . . 133

CONCURRENT AND PAST SMOKING HABITS . . . . . . . . . 135

RELATIONSHIPS BETWEEN CIGARETTE SMOKING AND DIET FROM

OBSERVATIONAL STUDIES . . . . . . . . . . . . . 135

CIGARETTE SMOKING AND FOOD PATTERNS . . . . . . . . . 135

Food items consumed . . . . . . . . . . . . . . . . . . . . . . 135

Social class . . . . . . . . . . . . . . . . . . . . . . . . . . . 136

CIGARETTE SMOKING AND NUTRIENT INTAKES . . . . . . . 137

Macronutrient intakes . . . . . . . . . . . . . . . . . . 137

Micronutrient intakes . . . . . . . . . . . . . . . . . . . . . . . . . 141

Regional variations . . . . . . . . . . . . . . . . 141

Social class . . . . . . . . . . . . . . . . . . . . . . . . 143

RELATIONSHIPS BETWEEN CIGARETTE SMOKING AND DIET FROM
EXPERIMENTAL STUDIES

SMOKING CESSATION AND BODY WEIGHT . . . . . . . . . . . . 144

SMOKING CESSATION AND NUTRIENT INTAKES . . . . . . . . 145

Macronutrient intakes . . . . . . . . . . . . . . . . . . . 145

Micronutrient intakes . . . . . . . . . . . . . . . . 145

Other potential causes of weight gain . . . . . . . . . . . . . . . 145

RELATIONSHIPS BETWEEN NUTRIENT INTAKE AND CIGARETTE
SMOKING AND CORONARY HEART DISEASE RISK FACTORS . 146

ANTHROPOMETRY . . . . . . . . . . . . . . 146

LIPIDS . . . . . . . . . . . . . . . . . 147

OTHER RISK FACTORS . . . . . . . . . . . . . . . . . 147

CONCLUSIONS AND FUTURE WORK . . . . . . . . . . . . . 149

REFERENCES . . . . . . . . . . . . . . . 150 


\section{INTRODUCTION}

Smoking has been described as the largest preventable cause of mortality (Secretary of State for Health, 1991). It accounts for more than one third of all deaths in middle age. Shaper et al. (1985) found male smokers were at three times the risk of heart disease compared with non-smokers. There is also concern over the possible detrimental effects on health of passive smoking. Smoking cessation is associated with a substantial reduction in risk, possibly by $50 \%$ within 5 years (Doll \& Peto, 1976; Cook et al. 1986).

In 1988 , percentages of the adult population currently smoking were $33 \%$ for men (nonmanual $24 \%$ and manual workers $40 \%$ ) and $30 \%$ for women (non-manual $25 \%$ and manual workers $36 \%$ ) which is a decrease from 1980 levels of 42 and $37 \%$ respectively (Department of Health, 1991a). Although rates have declined a large proportion of the adult population still smokes. Smoking rates in adolescents may be rising. Therefore, smoking will continue to be a major source of public health problems for the foreseeable future.

Smoking cigarettes may be associated with a change in dietary habits, both in food pattern and in nutrient intake, which may contribute to the increased risk of coronary heart disease in smokers compared with non-smokers. Conversely, quitting the habit may be followed by dietary changes which reduce coronary risk. Thus, reduction in coronary heart disease on quitting may be partly explained by dietary changes.

The objectives of this review are firstly to examine dietary data in different smoking categories - cigarette smokers, ex-smokers and life-long non-smokers - in relation to food pattern and nutrient intakes (and compare with dietary goals); secondly to examine the effects of social class and region of habitation on the food patterns and nutrient intakes of smokers and non-smokers (and compare them with national dietary recommendations); thirdly to examine the effects of smoking cessation on food patterns and nutrient intakes; and lastly to look at the importance of these dietary differences in relation to coronary heart disease.

\section{PROBLEMS ASSOCIATED WITH THE INTERPRETATION OF STUDIES}

Before reviewing the studies on smoking and diet it is important to consider a number of methodological issues such as the definition of smoking, design of studies and assessment of diet which affect the interpretation of the literature.

\section{DEFINITION OF SMOKING}

Smoking categories in general are defined as smokers, ex-smokers and non-smokers. However, precise definitions vary between studies. Groups of smokers include those currently smoking cigarettes but may also include pipe and cigar smokers (Fulton et al. 1988; Cade \& Margetts, 1991). Some authors have specified regular smokers as those smoking a minimum number of cigarettes per day (e.g. at least one cigarette daily (Whichelow et al 1988), seven daily (Klesges et al. 1990) and fifteen daily (Haste et al. 1990)). Never smokers are life-long non-smokers and ex-smokers are those who smoked in the past.

The term non-smokers refers to subjects not currently smoking; however, these may include never and/or ex-smokers and also pipe, cigar or infrequent smokers. This nonsmoking category was used by Fehily et al. (1984); Fulton et al. (1988); Whichelow et al. (1988); Whichelow (1989); Gregory et al. (1990); Klesges et al. (1990); Subar et al. (1990); 
Whichelow \& Erzinglioglu, (1990); Strain et al. (1991). Haste et al. (1990) examined current smokers and lifelong non-smokers.

Never smokers, ex-smokers and smokers were examined separately by Larkin et al. (1990), Bolton-Smith et al. (1991), Cade \& Margetts (1991), and Troisi et al. (1991). In general, no consideration has been given to time since quitting with the exception of Larkin et al. (1990) who defined ex-smokers as those who had stopped smoking for one year or more.

In this review we have used the following smoking categories: never smokers for lifelong non-smokers and non-smokers to refer to subjects not currently smoking, as it is not always possible to differentiate between never and ex-smokers and smokers which may include pipe or cigar smokers. It would make comparisons between studies easier if there were agreement on definitions of smoking categories. A possible suggestion for smoking categories is current smokers (smoking at least one cigarette daily), life-long non-smokers (subjects who have never smoked), ex-smokers (defined by time since quitting, for example those who had quit for more than one year). Small groups such as cigar, pipe and infrequent cigarette smokers could be either excluded from the analysis or analysed as a separate group.

Smoking status is self-reported with no validation in most observational studies. However, studies of smoking cessation usually employ a method of validation of smoking status, which is most commonly the measurement of cotinine (salivary or serum), a metabolite of nicotine. Lee (1988), in his review of seven studies using cotinine or nicotine estimates, found that $2 \cdot 2 \%$ of smokers misreported smoking status. Defining someone as a non-smoker when they are a smoker clearly gives a conservative bias to any comparisons between these groups. At best most markers used can detect smoking in the last few days, but as yet there is no marker suitable for long term validation. Therefore, markers are useful for determining regular smokers but may not detect intermittent smokers or distinguish between a subject who has never smoked and an ex-smoker.

Several studies have examined dietary differences in relation to number of cigarettes smoked. Without use of a biochemical measurement or specific questions on smoking (such as those on inhalation and amount of the cigarette that is smoked, as used by Troisi $e t$ al. (1991) this may be difficult to interpret.

When looking at a dose-response relationship between smoking and diet, subjects are usually classified as light, moderate or heavy smokers. However, the number of cigarettes smoked in each category varies between studies, e.g. Fulton et al. (1988) and Larkin et al. (1990) used the following categories for light, moderate and heavy smokers: one to ten, eleven to twenty and more than twenty cigarettes per day, whereas Fehily et al. (1984) and Subar et al. (1990) used one to fourteen, fifteen to twenty-four and twenty-five or more cigarettes daily as their categories. Sutton et al. (1982), however, showed that total volume of smoke puffed from a cigarette was a more important determinant of peak blood nicotine concentration than nicotine or tar yield of cigarettes, length of cigarette smoked or reported number of cigarettes smoked. We consider it to be important that when investigating a dose-response effect of smoking on diet either a biochemical marker should be used or a questionnaire included on smoking habit incorporating questions on inhalation and amount of cigarette smoked.

\section{DIETARY SURVEY METHODOLOGY}

A variety of different techniques was used to assess diet. These included 24-hour recall (Larkin et al. 1990; Subar et al. 1990), food frequency questionnaire (Whichelow et al. 1988; Whichelow, 1989; Klesges et al. 1990; Whichelow \& Erzinglioglu, 1990; Bolton- 
Smith et al. 1991; Troisi et al. 1991), one day food records (Cade \& Margetts, 1991), and weighed inventory (Fehily et al. 1984; Fulton et al. 1988; Gregory et al. 1990; Haste et al. 1990; Strain et al. 1991).

Each of these dietary methods has strengths and weaknesses. In any assessment of diet there will be measurement error and it is important to assess how this may affect the relationships reported. Ideally the potential effect of measurement error should be assessed in each study and this can be done by repeating the assessment in a statistically valid subsample. Up to the present this has not been done.

The selection of the appropriate method of assessing diet depends on the objective of the study. If the intakes of individuals are required a more precise method is necessary than if a group mean estimate is required. If a method suitable only for estimating group means (24-hour recall or record) is used to rank individuals there is likely to be considerable subject misclassification. Practical considerations may also influence the choice of method. Intakes assessed using the weighed inventory method may be more precise, but may not reflect the longer term usual diet. One-day records and recalls are easier for subjects to complete and may therefore be a more accurate reflection of the diet at the time of recording. The food frequency questionnaire estimate of intake may not be as precise as that obtained from the weighed inventory, but it may more realistically reflect the longer term dietary patterns. Absolute differences between studies in mean levels of nutrient intakes may reflect, therefore, the differences between methods of assessment as well as real differences. Also, because of the differences in methods used, the ranking of individuals in the different studies may differ; the group mean estimates, however, should reflect the true measure of central tendency, and for the purposes of this review the group means have been used.

Of major concern in any comparison between different groups in a study is the possibility of bias. In the context of this review the concern is that smokers and non-smokers participate (and do not participate) in the study in the same way, including the way they complete their dietary assessment. If they do not participate in the study in the same way it is difficult to ascertain whether the reported differences are real or simply due to the different way in which they participated in the study.

In this review we have selected studies which we believe have minimized the possibilities of bias, or at least have provided sufficient information to assess the potential effect bias may have had on the interpretation of the study.

While there have been relatively few studies which have published food intake patterns, more data are available on nutrient intakes. Because of the varying quality of the published literature, criteria for inclusion of studies have been adopted:

(1) The study had to describe clearly how the sample was selected and the sample had to be representative of a wider adult population.

(2) The number of subjects was statistically valid.

(3) The dietary methods had to be appropriate and described in sufficient detail-methods used included food diary methods, food frequency questionnaires, 24-hour records or recalls.

(4) Details about other potential confounding variables were reported.

The review has also focused mainly on those studies investigating UK samples. All the studies fulfilling the criteria were cross-sectional in design. It is not possible in crosssectional studies where diet, smoking habits and other factors are assessed at the same time to determine whether the dietary patterns were established before the smoking habit. Ideally, dietary patterns should be assessed before the subject starts smoking in order to 
estimate the effect of taking up smoking on dietary habits. As far as we are aware, no such information has been published.

\section{CONCURRENT AND PAST SMOKING HABITS}

Ideally, to investigate the relationships between smoking and dietary habits, a group of lifelong non-smokers should be studied and the effect of commencing smoking on diet measured. This would require a study of children or young adults that would raise both practical and ethical problems. An alternative approach is to study the changes consequent on giving up smoking. These data are limited to experimental studies in which smokers volunteer to stop smoking. There is no information, as yet, on random samples of smokers as they quit smoking. It is, therefore, not possible to determine whether the differences in dietary patterns between different categories of smokers represent lifetime differences or change associated with smoking.

Friedman et al. (1979) compared baseline characteristics of smokers who became exsmokers with those who continued to smoke. They found that those who quit had a higher body weight and consumed less alcohol. In fact, those who quit appeared to be more like non-smokers than smokers on the above criteria.

\section{RELATIONSHIPS BETWEEN CIGARETTE SMOKING AND DIET FROM OBSERVATIONAL STUDIES}

Differences in food patterns and nutrient intakes between smoking categories and the separate effects of social class and region of habitation are examined.

\section{CIGARETTE SMOKING AND FOOD PATTERNS}

Observational data on differences in food patterns are reviewed together with possible influences of social class. There are no data on regional variation of food patterns by smoking category.

\section{Food items consumed}

Differences in types of foods reported to be consumed by smokers and non-smokers from the Health and Lifestyle Survey (Whichelow et al. 1988; Whichelow, 1989; Whichelow \& Erzinglioglu, 1990) after adjustment for age and socio-economic status are summarized in Table 1. Smokers more frequently consumed butter, chips, fried food and processed meats, alcohol and tea and coffee and less frequently fruit and fruit juice, salads, puddings, cakes and biscuits, breakfast cereals and 'brown bread' (included all bread except white) and polyunsaturated margarines and low fat spreads. Smokers, particularly heavy smokers, were also less likely to eat breakfast than non-smokers. Subar et al. (1990) reported that after adjusting for poverty index ratio, age, energy intake and sex, more smokers than nonsmokers over a $24-\mathrm{h}$ period consumed whole milk and bacon/luncheon meat. There was no difference between smoking categories in red meat consumption, although non-smokers ate more vegetables, fruit, poultry/fish, skimmed milk and vitamin supplements than smokers. The only study to calculate amounts of food eaten was that of Larkin et al. (1990) who found that smokers ate more eggs, sugar, and beverages (both alcoholic and non-alcoholic, with the exception of diet drinks) and less fruit and vegetables.

Information from weighed inventory studies is limited, although Strain et al. (1991) and Fulton et al. (1988) reported that smokers consumed less cereal products and cakes and 
Table 1. Differences between current smokers and non-smokers in the frequency of consumption of selected foods

\begin{tabular}{lll}
\hline $\begin{array}{c}\text { Consumed more } \\
\text { frequently by } \\
\text { smokers }\end{array}$ & $\begin{array}{c}\text { Consumed more } \\
\text { frequently by } \\
\text { non-smokers }\end{array}$ \\
& Alcohol & $\begin{array}{l}\text { Biscuits and cakes } \\
\text { Breakfast cereals }\end{array}$ \\
& $\begin{array}{l}\text { Butter } \\
\text { Chips }\end{array}$ & $\begin{array}{l}\text { Frown bread' } \\
\text { Fried foods }\end{array}$ \\
Processed meats & Low fat milk juice \\
Tea and coffee & Jam \\
Sugar in drinks & Polyunsaturated and \\
low fat margarines & Puddings and light \\
& desserts \\
& Salads \\
\hline
\end{tabular}

Sources: Whichelow et al. (1988); Whichelow (1989); Whichelow \& Erzinglioglu (1990).

Table 2. Percent differences between smokers and non-smokers for amounts and type of spreads used by gender and social class

$($ Non-smokers $=100 \%)$

\begin{tabular}{|c|c|c|c|c|}
\hline & \multicolumn{2}{|c|}{ Men } & \multicolumn{2}{|c|}{ Women } \\
\hline & Non-manual & Manual & Non-manual & Manual \\
\hline Butter & 124 & 110 & 119 & 120 \\
\hline Margarine & 114 & 116 & 107 & 105 \\
\hline $\begin{array}{l}\text { Polyunsaturated } \\
\text { margarine }\end{array}$ & 54 & 59 & 88 & 64 \\
\hline Low fat margarine & 63 & 56 & 58 & 48 \\
\hline None & 170 & 96 & 92 & 154 \\
\hline Amount & 122 & 131 & 135 & 134 \\
\hline
\end{tabular}

Source: Whichelow (1989).

puddings than non-smokers. Fulton et al. (1988) also reported a higher consumption of polyunsaturated margarines by non-smokers compared with smokers. Gregory et al. (1990) found that a 'traditional' meat and vegetable diet was associated with smoking cigarettes. A 'traditional' diet included the following food items; white bread, bacon, ham, sausage, meat pies, vegetables and potatoes (in any form). It also tended to be a diet high in energy and alcohol.

Despite differences in methods, results from the studies show that both men and women smokers eat less fruit and vegetables, sweet products and polyunsaturated margarines than non-smokers, but more processed meats, white bread and beverages including alcohol, tea and coffee and were more likely to use sugar than non-smokers.

Social class

Whichelow (1989) looked at amount and choice of spread used by smokers and nonsmokers of differing social class as assessed by occupation (Table 2). Smokers showed a preference for butter compared with non-smokers with the smallest difference being for 
men with manual occupations. Smokers tended to use margarine rather than low fat spread or polyunsaturated margarine compared with non-smokers. For men differences between manual and non-manual occupation groups were small. Women smokers of non-manual occupation groups tended to use more polyunsaturated margarine, although still less than for non-manual non-smokers. The greatest difference was in those who used no spread; among men with non-manual occupations more smokers than non-smokers used no spread; however, in women it was in the manual group in which smokers were more likely to use no spread. Smokers, irrespective of occupation group, used more spread than nonsmokers. This appeared to be the result of using more spread per slice of bread than consuming greater amounts of bread.

There is little information on social class differences and smoking categories. There are some data on choice of fat spreads. For men, more non-manual smokers than non-smokers used no spread on bread. In women, smokers of non-manual occupations were more likely to use polyunsaturated fats and those from the manual group more likely to use no spread than non-smokers in their respective groups.

These data demonstrate that the whole dietary pattern of smokers is different from that of non-smokers.

\section{CIGARETTE SMOKING AND NUTRIENT INTAKES}

Differences in the consumption of macronutrients and micronutrients by smoking category are reviewed and compared with dietary recommendations. It has not always been possible to ensure that definitions of nutrients have been used in the same way in all studies. For example, it is not always clear whether percent energy derived from protein, fat and carbohydrate takes into account energy from alcohol. If smokers drink more alcohol this may distort comparisons of percent energy between smokers and non-smokers in the same study and between groups in different studies. The term dietary fibre used here relates to the previous definition of fibre and not to non-starch polysaccharide. At present there are no data on non-starch polysaccharide intakes by smoking category. The possible effects of social class and regional variation are also discussed.

\section{Macronutrient intakes}

Two studies have shown lower energy intakes in men who had never smoked compared with men who smoked (Bolton-Smith et al. 1991; Cade \& Margetts, 1991). In these two studies energy intakes in the male smokers were 10.54 and $11.0 \mathrm{MJ}$ and in never smokers $9 \cdot 28$ and $10.2 \mathrm{MJ}$ respectively with intakes of ex-smokers intermediate. Other workers in USA found similar trends although not statistically significant for energy (Klesges et al. 1990; Subar et al. 1990; Troisi et al. 1991).

Gregory et al. (1990) showed that women who smoked consumed less energy than nonsmokers. Similar trends although not statistically significant were apparently found by Strain et al. (1991) (6.9 and 7.29 MJ for smokers and non-smokers). However, both BoltonSmith et al. (1991) and Cade \& Margetts (1991) found marginally higher intakes in women smokers compared with never smokers with lowest intakes in ex-smokers. It is possible that the low intakes in ex-smokers are a result of dieting.

Several studies have looked at both men and women, which gives the opportunity to look at differences between men and women in the same populations while using identical methods. Men who smoke have been shown in some studies to consume a diet higher in energy than non-smokers (Bolton-Smith et al. 1991; Cade \& Margetts, 1991) with exsmokers intermediate, but the pattern is less clear in women. This may be a result of some women using cigarette smoking to control their weight and energy intakes (Rodin, 1987). 
Protein consumption, expressed as \% energy (alcohol included), derived from food frequency questionnaires, has been shown to be lower in men smokers compared with nonsmokers (Klesges et al. 1990; Bolton-Smith et al. 1991). Absolute intakes assessed from a weighed intake have also shown statistically significantly lower intake of protein (Gregory et al. 1990; Strain et al. 1991). In women, Bolton-Smith et al. (1991) found significantly lower protein intakes expressed as \% energy in smokers compared with never and exsmokers.

Total carbohydrate consumption does not seem to differ between smoking categories (Fehily et al. 1984; Fulton et al. 1988; Gregory et al. 1990). However, sugar intake in men was statistically significantly higher in smokers compared with non-smokers, expressed as absolute values or \% energy (Gregory et al. 1990; Bolton-Smith et al. 1991; J. E. Cade, unpublished data). In women, sugar intake ( $\mathrm{g}$ ) was lower in smokers compared with nonsmokers (Strain et al. 1991) but higher as \% energy (Bolton-Smith et al. 1991). The latter also showed that men who smoked consumed a higher \% energy as sugar than women $(17 \cdot 7$ and 16.4 respectively).

In these studies, women smokers consumed a diet higher in fat as \% energy (39.9 and 38) than men (34.3 and 36) (Bolton-Smith et al. 1991; Cade \& Margetts, 1991) with alcohol energy counted. These differences between men and women may be a result of higher alcohol intakes in men. In general, differences in fat intakes between smoking categories are limited to quality of fat consumed. Some workers have looked at \% energy contribution from saturated fatty acids using questionnaire methods (Bolton-Smith et al. 1991; Troisi et al. 1991) and weighed intakes (Gregory et al. 1990) and found higher intakes in men smokers compared with never smokers and ex-smokers. However, there were large differences in saturated fat intakes as \% energy for smokers between the studies $(15 \cdot 2$ and $26.2 \%$ for Bolton-Smith et al. (1991) and Troisi et al. (1991) respectively). Other studies (Fulton et al. 1988 \& J. E. Cade, unpublished) found no difference in saturated fatty acids expressed as $g$ in men non-smokers and smokers, with the exception of Gregory et al. (1990) who found higher intakes in smokers compared with non-smokers. Fulton et al. (1988) found both linoleic acid and total polyunsaturated fat intakes were lower in smokers compared with non-smokers. This was confirmed by lower linoleic acid \% in adipose tissue (an indication of long term dietary intake of this fatty acid-Beynen et al. 1980) of smokers compared with non-smokers $(8 \cdot 4$ and $9 \cdot 3 \%$ respectively). In fact, those men smoking $>$ twenty cigarettes daily had the lowest proportion of adipose tissue linoleic acid $(7.9 \%)$ compared with those smoking between eleven and twenty per day $(8.8 \%)$ and ten or less $(8.6 \%)$. Polyunsaturated fat intake was also lower in both men and women smokers (Bolton-Smith et al. 1991) compared with never smokers. Mean polyunsaturated to saturated $(\mathrm{P}: \mathrm{S})$ fat ratios have been calculated for several studies and are in the range 0.22-0.30 for men and women smokers and 0.26-0.35 for non-smokers in UK (Fulton et al. 1988; Bolton-Smith et al. 1991; Cade \& Margetts, 1991).

Gregory et al. (1990) and Bolton-Smith et al. (1991) found that men and women smokers consumed more alcohol as \% energy than non-smokers $(7 \cdot 1$ and 5.0 for men and 3.0 and 1.9 for women; Bolton-Smith et al. 1991). Strain et al. (1991) also found a higher alcohol intake in men and women who smoked compared with non-smokers. Fehily et al. (1984) found that male smokers consumed slightly more alcohol than non-smokers although this was not statistically significant. A recent study of 17-year-old adolescent smokers showed that more smokers than non-smokers regularly drank $8 \mathrm{~g}$ or more of alcohol a day (Townsend et al. 1991).

Dietary fibre intakes have been shown to be lower in smokers than non-smokers both as absolute amounts (Fehily et al. 1984; Fulton et al. 1988; Gregory et al. 1990; Klesges et al. 1990; Subar et al. 1990; Strain et al. 1991; Cade \& Margetts, 1991; Troisi et al. 1991) 
Table 3. Comparison of nutrient intakes between smokers and non-smokers from five UK studies for men and four for women using food diary methods

(Numbers of studies showing no statistically significant differences (NS) and those showing statistically significant differences (SD))

\begin{tabular}{|c|c|c|c|c|c|}
\hline \multirow[b]{2}{*}{ Nutrient } & \multicolumn{2}{|c|}{ Men } & \multicolumn{3}{|c|}{ Women } \\
\hline & NS & SD & NS & SD & \\
\hline Energy (kcal/MJ) & $1,2,3,6$ & $(++) \dagger$ & $4,5,6$ & 3 & $(--)$ \\
\hline Protein $(\mathrm{g})$ & $1,2,5$ & $(--)$ & All & - & \\
\hline Fat $(g)$ & All & - & All & - & \\
\hline \multicolumn{6}{|l|}{ Polyunsaturated } \\
\hline fat $(\mathrm{g})$ & 5 & $(--)$ & 5 & - & \\
\hline Saturated fat $(\mathrm{g})$ & 5,2 & - & 5 & - & \\
\hline$P: S$ & - & $2,3,5(--)$ & 3 & 5 & $(-)$ \\
\hline Carbohydrate (g) & $1,2,5$ & $6 \quad(---)$ & 4,5 & 6 & $(-)$ \\
\hline Sugar $(g)$ & 1,6 & $3,5 \quad(+)$ & 3,5 & 6 & $(-)$ \\
\hline Fibre $(\mathrm{g})$ & - & $(---)$ & - & All & $(---)$ \\
\hline Alcohol (g) & $1,2,3$ & $(+++)$ & $\ldots$ & 3,6 & $(++)$ \\
\hline Retinol $(\mu \mathrm{g})$ & 3,5 & $(-)$ & 3,4 & 5 & $(-)$ \\
\hline$\beta$-carotene $(\mu \mathrm{g})$ & - & $1,5 \quad(-\infty)$ & - & 4,5 & $(--)$ \\
\hline Thiamin (mg) & - & $1,3,6(--)$ & 6 & 3,4 & $(--)$ \\
\hline Ascorbic acid (mg) & 5 & $1,3 \quad(--)$ & - & 3,4 & $5(--)$ \\
\hline Vitamin $\mathrm{E}(\mathrm{mg})$ & - & $5,6 \quad(--)$ & - & $4,5,6$ & $6(--)$ \\
\hline Folate $(\mu \mathrm{g})$ & 6 & $(--)$ & - & $3,4,6$ & $6(-)$ \\
\hline Calcium (mg) & 1,3 & $6 \quad(-)$ & 4 & 3,6 & $(-)$ \\
\hline Iron $(\mathrm{mg})$ & - & $1,3,6(\cdots)$ & 6 & 3,4 & $(--)$ \\
\hline
\end{tabular}

$\dagger(+)$, Higher intakes in smokers compared with non-smokers; $(-)$, lower intakes in smokers compared with non-smokers.

Sources:

1. Fehily et al. (1984); 493 men aged 45-59 years adjusted for social class.

2. Fulton et al. (1988); 162 men aged $45-54$ years adjusted for social class.

3. Gregory et al. (1990); 2197 men and women aged 16-64 years adjusted for social class and age.

4. Haste et al. (1990); 206 pregnant women adjusted for social class and height.

5. Cade \& Margetts, (1991) and unpublished; 2340 men and women aged 35-54 years.

6. Strain et al. (1991); 590 men and women aged 16 64 years adjusted for age and social class.

and nutrient densities $(\mathrm{g} / 1000 \mathrm{kcal})$ (Haste et al. 1990; Larkin et al. 1990; Bolton-Smith et al. 1991). Table 3 summarizes data from six studies carried out in the UK (five studies with men, four with women) using food diary methods (Fehily et al. 1984; Fulton et al. 1988; Gregory et al. 1990; Haste et al. 1990; Cade \& Margetts, 1991; J. E. Cade, unpublished; Strain et al. 1991). Studies with statistically significant differences (SD) are shown together with studies finding similar results for smokers and non-smokers. Plus and minus signs indicate the direction of differences between smokers and non-smokers. Table 3 shows that for $\mathrm{P}: \mathrm{S}$ ratio and fibre there is consistent agreement between studies with smokers consuming less than non-smokers.

Differences in macronutrients between smokers and non-smokers, except alcohol which is higher in smokers compared with non-smokers, are relatively small.

Table 4 compares intakes from five UK studies with current national dietary guidelinés and reference values. Two studies included in Table 3 have been excluded from this table because nutrient values were not available (Gregory et al. 1990) or subjects were pregnant (Haste et al. 1990). Sources of guidelines used were: Dietary references values (Department of Health, $1991 b$ ); estimated average requirements (EAR) for energy; reference nutrient intakes for protein and ascorbic acid; dietary reference value for fat as a percentage of 
Table 4. Comparison of nutrient intakes of smokers from five British studies with national nutritional guidelines

\begin{tabular}{|c|c|c|c|c|c|}
\hline \multirow[b]{2}{*}{ Nutrient } & \multicolumn{3}{|c|}{ National guidelines } & \multicolumn{2}{|c|}{ Smokers } \\
\hline & Source & Men & Women & Men & Women \\
\hline Energy (MJ) & EAR* & $10 \cdot 6$ & $8 \cdot 0-8 \cdot 1$ & $\begin{array}{c}10 \cdot 1-11 \cdot 4 \\
(3,5,1,2,4)\end{array}$ & $\begin{array}{c}6 \cdot 9-7 \cdot 6 \\
(5,2,1)\end{array}$ \\
\hline Protein (g) & RNIt & $55 \cdot 5$ & $45 \cdot 0$ & $\begin{array}{l}81 \cdot 0-93 \cdot 0 \\
(5,3,2,4)\end{array}$ & $\begin{array}{c}58 \cdot 0 \& 62 \cdot 6 \\
(5,2)\end{array}$ \\
\hline $\begin{array}{l}\text { Fat } \\
\quad(\% \text { energy })\end{array}$ & $\mathrm{DRV} \dagger$ & 33 & 33 & $\begin{array}{c}34 \cdot 3 \& 36 \\
(1,2)\end{array}$ & $\begin{array}{c}38 \& 39 \cdot 9 \\
(2,1)\end{array}$ \\
\hline $\mathrm{P}: \mathrm{S}$ & DRV & 0.45 & $0 \cdot 45$ & $\begin{array}{c}0 \cdot 23-0 \cdot 30 \\
(1,4,2)\end{array}$ & $\begin{array}{c}0.22 \& 0.29 \\
(1,2)\end{array}$ \\
\hline Fibre $(g)$ & NACNE $\$$ & 25 & 25 & $\begin{array}{l}17 \cdot 5-19 \cdot 1 \\
(2,3,4,5)\end{array}$ & $\begin{array}{c}13 \cdot 1 \& 14 \cdot 7 \\
(2,5)\end{array}$ \\
\hline Sugar $(g)$ & NACNE & 93 & 93 & $\begin{array}{r}97-119 \\
(5,3,2)\end{array}$ & $\begin{array}{c}65 \& 73 \\
(5,2)\end{array}$ \\
\hline Alcohol $(\mathrm{g})$ & DRV & 24 & 16 & $\begin{array}{l}21-34 \\
(3,5,4)\end{array}$ & $\begin{array}{l}7 \cdot 1 \\
(5)\end{array}$ \\
\hline $\begin{array}{l}\text { Ascorbic } \\
\quad \text { acid }(\mathrm{mg})\end{array}$ & RNI & 40 & 40 & $\begin{array}{c}44 \cdot 7 \& 47 \cdot 7 \\
(3,2)\end{array}$ & $\begin{array}{l}41 \cdot 7 \\
(2)\end{array}$ \\
\hline $\begin{array}{l}\text { Vitamin } E_{\text {, }} \\
\text { (mg) }\end{array}$ & $\begin{array}{c}\text { Safe intake } \\
\text { DRV }\end{array}$ & 4 & 3 & $\begin{array}{c}4 \cdot 2 \& 4.8 \\
(5,2)\end{array}$ & $\begin{array}{c}3 \cdot 3 \& 3 \cdot 5 \\
(5,2)\end{array}$ \\
\hline
\end{tabular}

\footnotetext{
* EAR, estimated average requirement; Department of Health $(1991 b)$.

$\dagger$ DRV, dietary reference values; Department of Health (1991b).

$\$$ RNI, reference nutrient intake; Department of Health $(1991 b)$.

$\S$ NACNE (1983).

$\|$ Order of studies from lowest to highest nutrient value.

Sources (shown in parentheses):

1. Bolton-Smith et al. (1991); 9692 men and women aged 40-59 adjusted for age and social class.

2. Cade \& Margetts, (1990), (1991) unpublished; 2340 men and women aged 35-54 years.

3. Fehily et al. (1984); 493 men aged $45-59$ years adjusted for social class.

4. Fulton et al. (1988); 162 men aged 45-54 years adjusted for social class.

5. Strain et al. (1991); 590 men and women aged 16-64 years adjusted for age and social class.
}

energy, and a safe intake for vitamin E; the National Advisory Committee on Nutrition Education (NACNE, 1983) recommendations for fat, fibre and sugar; and Committee on Medical Aspects of Food Policy (COMA, 1984) Panel on Diet in Relation to Cardiovascular Disease for $\mathrm{P}: \mathrm{S}$ ratio.

Reported energy intakes in men are similar to the recommendations, with the exception of the study by Fehily et al. (1984) who showed lower intakes. In women measured energy intakes were all lower than the EAR. Studies carried out in USA (Larkin et al. 1990; Subar et al. 1990) also measured low intakes at 1629 and $1591 \mathrm{kcal}$ respectively. Protein intakes in men and women smokers were in excess of the reference nutrient intake values.

Dietary recommendations for fat consumption as \% energy are to reduce fat to $33 \%$ (Department of Health, $1991 \mathrm{~b}$ ) or $34 \%$ (NACNE, 1983). In studies in which percentage contributions to energy are calculated neither smokers nor non-smokers achieved this goal with the exception of the study on men by Bolton-Smith et al. (1991). However, when the food frequency method used in this study was validated in comparison with a weighed inventory, the food frequency questionnaire underestimated fat consumption by $6.5 \%$ that of weighed intakes (Bolton-Smith \& Milne, 1991). This under-reporting of intake may therefore account for the increased proportion of subjects achieving the goal for lower fat intakes. 
The aim with regard to the quality of fat consumed is to decrease saturated fats to $10 \%$ of total energy intake and increase $P: S$ ratio to 0.45 (COMA, 1984). Although mean $P: S$ ratios do not reach this value, some subjects, in particular women from higher socioeconomic groups, may do so whereas men smokers with manual occupations will be less likely to.

Recommendations for alcohol consumption are that men should not drink more than 21 units (168 g) and women 14 units (112 g) of alcohol weekly (Department of Health, $1991 \mathrm{~b}$ ). Most studies found that on average men and women reported drinking less than the recommended limits with the exception of Scottish male manual workers who smoked (Fulton et al. 1988).

Smokers appear to consume similar macronutrient intakes to non-smokers for energy, fat and carbohydrate but with possible differences in protein and sugar intakes. There is agreement between the studies showing lower intakes of dietary fibre, lower $\mathrm{P}: \mathrm{S}$ ratio and higher alcohol intakes in smokers compared with non-smokers. In relation to goals, men smokers had similar energy intakes to recommendations but women in both UK and USA had intakes below recommendations. Protein and fat intakes were in excess of recommendations. $\mathrm{P}: \mathrm{S}$ ratios failed to meet the goal of $0 \cdot 45$, but alcohol limits were not exceeded with the exception of the Scottish men.

\section{Micronutrient intakes}

Lower intakes of micronutrients have been found in smokers compared with nonsmokers expressed both in g (Fehily et al. 1984; Subar et al. 1990; Strain et al. 1991; Cade \& Margetts, 1991) and as nutrient density (g/1000 kcal) (Haste et al. 1990; Larkin et al. 1990; Bolton-Smith et al. 1991). In particular, amounts of the antioxidant vitamins ascorbic acid, vitamin $\mathrm{E}, \beta$-carotene are lower in smokers than non-smokers. Amounts of ascorbic acid consumed by women who smoke are between 65 and $80 \%$ of non-smokers (Haste et al. 1990; Larkin et al. 1990; Bolton-Smith et al. 1991). Women appear to consume a diet which has a higher micronutrient density (Bolton-Smith et al. 1991) than men, although absolute intakes are less as a result of lower energy intakes in women.

Table 3 shows that for most micronutrients there is consistent agreement between studies, with smokers consuming less than non-smokers. Table 4 compares micronutrient intakes from UK studies; reference nutrient intakes are used for ascorbic acid and a safe intake used for vitamin $\mathrm{E}$. Both ascorbic acid and vitamin $\mathrm{E}$ intakes reached the recommended intakes.

There is general agreement between studies that smokers consume a diet which is lower in micronutrients than non-smokers but intakes are not considered low in comparison with dietary goals. Requirements for micronutrients may, however, be higher in smokers than non-smokers, and the goals may therefore not be an appropriate frame of reference in this group.

\section{Regional variations}

Table 5 looks at differences in diets of male smokers and non-smokers between different regions in the UK. Studies included in the table used the weighed inventory method of dietary assessment, except the study carried out in three towns in England (Ipswich, Stoke and Wakefield) in which a one-day record with estimated portion sizes was used (Cade \& Margetts, 1991). Smokers were classified into non-smokers (never for one study, Cade \& Margetts, 1991) and current smokers. In the Scottish study (Fulton et al. 1988), manual and non-manual occupation groups are presented separately. There is little difference in energy intakes between the regions. Energy intakes of smokers as percent of non-smokers were 
Table 5. Regional comparison of levels of nutrients for male smokers compared with non-smokers

(Percentage difference of smokers compared with non-smokers (non-smokers $=100 \%)$ )

\begin{tabular}{|c|c|c|c|c|c|}
\hline \multirow{4}{*}{$\begin{array}{l}\text { Regions } \\
\text { Age (years) } \\
\text { Number } \\
\text { of subjects }\end{array}$} & \multirow{4}{*}{$\begin{array}{c}\text { England } \\
\begin{array}{c}35-54 \\
512\end{array}\end{array}$} & \multirow{3}{*}{$\begin{array}{c}2 \\
\text { Wales } \\
45-59\end{array}$} & \multirow{3}{*}{$\begin{array}{c}3 \\
\text { Northern } \\
\text { Ireland } \\
16-64\end{array}$} & \multicolumn{2}{|c|}{4} \\
\hline & & & & \multicolumn{2}{|c|}{ Scotland } \\
\hline & & & & \multicolumn{2}{|c|}{$45-54$} \\
\hline & & 77 & 111 & $\begin{array}{c}\text { Manual } \\
52\end{array}$ & $\begin{array}{c}\text { Non-manual } \\
25\end{array}$ \\
\hline Energy & 108 & 100 & 96 & 99 & 100 \\
\hline Protein & 104 & 99 & 93 & 94 & 101 \\
\hline Fat & 103 & 97 & 94 & 98 & 97 \\
\hline Carbohydrate & 106 & 100 & 88 & 94 & 100 \\
\hline Fibre & 85 & 86 & 84 & 90 & 86 \\
\hline Alcohol & - & 120 & 289 & 155 & 124 \\
\hline
\end{tabular}

Sources:

1. Cade \& Margetts (1990, 1991).

2. Fehily et al. (1984).

3. Strain et al. (1991).

4. Fulton et al. (1988).

similar for men in Scotland and Wales, but smokers in Northern Ireland consumed less energy than non-smokers, the opposite being reported in the English study.

Differences in protein, fat and carbohydrate intakes were similar between the regions although differences seemed larger in Northern Ireland but this could possibly be explained by a lower energy intake in smokers compared with non-smokers. Intakes of fibre were lower in smokers compared with non-smokers with no apparent regional variation. The largest variation between regions was in alcohol consumption, with smokers in Northern Ireland consuming nearly three times as much alcohol as non-smokers. In Wales and nonmanual Scots, the difference in alcohol consumption between smokers and non-smokers was smaller. Comparison of diets of women smokers and micronutrient intakes in men could not be made owing to insufficient data.

Similar trends in macro- and micronutrient intakes between smoking categories were seen in American studies (mainly 24-h recall and questionnaire methods) and UK studies (weighed inventories). However, there does appear to be a difference in quality of fat consumed. UK studies show that non-smokers consume a diet with a higher $\mathrm{P}: \mathrm{S}$ ratio resulting from a higher polyunsaturated intake in non-smokers and possibly a higher saturated fat intake in smokers. American studies by Subar et al. (1990) using a 24-h recall method found no differences in linoleic acid content of the diet of men and women smokers and non-smokers in different age bands although they showed a higher saturated fat intake in the older age bands, 30-74 years, for smokers compared with non-smokers. Troisi et al. (1991) using a questionnaire found higher saturated fat intakes in smokers compared with never and ex-smokers. Klesges et al. (1990) using the Willett Food Frequency Questionnaire found no differences in polyunsaturated and saturated fats as a percentage of energy between smoking categories. P:S ratios were not measured in the American studies but are likely to be in the same direction as in the UK studies although differences in saturated fat instead of polyunsaturated fat intake appear to account for differences between smokers and non-smokers in the $P: S$ ratio. If percentage differences of smokers compared with nonsmokers are calculated for linoleic acid between a Scottish study (manual workers) (Fulton 
et al. 1988) and an American study (A. F. Subar et al. unpublished), Scottish smokers consume $65 \%$ of the linoleic acid of non-smokers compared with $107 \%$ in the American study.

Regional differences in diets of smokers are small but further work needs to be carried out using the same dietary assessment method on a national sample of the population before any clear conclusions can be made. Within the UK there are differences in the consumption of alcohol by region. In comparison with USA, the main difference in the diet of smokers is the consumption of linoleic acid, with American smokers consuming higher intakes than smokers in UK but similar intakes to American non-smokers, although P:S ratios are probably similar to UK.

\section{Social class}

Fulton et al. (1988) found little difference in dietary habits between men smokers of manual and non-manual occupations (Table 5), although manual workers who smoked appeared to consume less carbohydrate and more alcohol than manual workers who did not smoke. However, if a different comparison is made between non-manual and manual workers who smoke, non-manual workers who smoke consumed a diet higher in fibre, lower in alcohol and P:S ratio than manual workers who smoke (106, 76 and $92 \%$ respectively). Similar trends were seen in non-smokers of different socio-economic status; higher fibre intake $(110 \%)$, lower alcohol intake $(95 \%)$ and higher $\mathrm{P}: \mathrm{S}$ ratio $(109 \%)$.

The study carried out by Haste et al. (1990) of pregnant women in London looked at differences between non-smokers and smokers of differing social class. Women whose husbands were employed in non-manual occupations consumed more energy, protein and fat than women whose husbands were employed in manual occupations for both nonsmokers and smokers. Among women whose husbands were employed in manual occupations fibre intakes were not statistically different across smoking groups $(15.4 \mathrm{~g}$, non-smokers and $12.9 \mathrm{~g}$, smokers) but larger differences were seen in women whose husbands were employed in non-manual occupations (22.9 and 13.1 g respectively). Similar trends were seen for ascorbic acid, vitamin $\mathrm{E}$ and $\beta$-carotene.

Information is limited but smoking appears to have a greater effect on diet, particularly on micronutrients, than social class. However, social class does have an effect within smoking groups especially in higher socio-economic groups.

Summary. While there were differences in the dietary methods used in the different studies, a number of general patterns emerge on the basis of comparisons within studies. There appear to be differences between smokers and non-smokers in the consumption of a wide range of foods leading to differences in many nutrients, particularly types of fat, dietary fibre and micronutrients. The diet of smokers compared with non-smokers tends to be less like those currently being recommended to reduce risk of disease.

\section{RELATIONSHIPS BETWEEN CIGARETTE SMOKING AND DIET FROM EXPERIMENTAL STUDIES}

Some prospective studies on the diets and anthropometry of smokers as they quit have been carried out. There is no information on differences by social class or regional variation:s

Studies reviewed here include those in which smokers quit for a number of weeks and do not include those investigating differences in taste perception by smoking category.

There is little information on changes in food patterns after cessation, with the exception of Stubbe et al. (1982) who found that extra snacks were eaten between meals. Subjects participating are generally volunteers and are not randomly selected from the general 
Table 6. Weight gain after smoking cessation by time since quitting

\begin{tabular}{|c|c|c|c|c|}
\hline \multirow[b]{2}{*}{ Study } & \multicolumn{2}{|c|}{ Subjects } & \multirow{2}{*}{$\begin{array}{c}\text { Weight } \\
\text { gain } \\
(\mathrm{kg})\end{array}$} & \multirow{2}{*}{$\begin{array}{c}\text { Time } \\
\text { since } \\
\text { (weeks) }\end{array}$} \\
\hline & $\begin{array}{l}\text { No. } \\
(\mathrm{M} / \mathrm{W})\end{array}$ & $\begin{array}{c}\text { Mean age } \\
\text { (years) }\end{array}$ & & \\
\hline Feher et al. (1990) & $12 / 18$ & 38 & 0 & 2 \\
\hline Stubbe et al. (1982) & $10 / 0$ & 38 & 1.8 & $4-6$ \\
\hline Dallosso \& James (1984) & $9 \dagger$ & 47 & $1 \cdot 4$ & 6 \\
\hline Rodin (1987) & $4 / 20$ & 42 & $1 \cdot 4$ & $6-8$ \\
\hline Stamford et al. (1986) & $0 / 13$ & 45 & $2 \cdot 2$ & 7 \\
\hline Hall et al. (1989) & $27 \dagger$ & 38 & $2 \cdot 3$ & $8-12$ \\
\hline Hall et al. (1989) & $27 \dagger$ & 38 & $4 \cdot 1$ & $22-26$ \\
\hline Stamford et al. (1986) & $0 / 3$ & 45 & $8 \cdot 2$ & 52 \\
\hline Shimokata et al. (1989) & $2680 \dagger$ & $19-102$ & $2 \cdot 3$ & 156 \\
\hline Williamson et al. (1991) & $409 / 359$ & $25-74$ & $2 \cdot 8 / 3 \cdot 8$ & $>52$ \\
\hline
\end{tabular}

$\dagger$ Total number of subjects, men + women.

population, unlike the observational studies. With the exception of Stubbe et al. (1982) who used a dietary questionnaire, the dietary method chosen is a prospective food record in which portions are recorded as household measures completed daily for the duration of the study (Stamford et al. 1986; Rodin, 1987) or a $3 \mathrm{~d}$ weighed food diary kept at five intervals during the study (Hall et al. 1989).

\section{SMOKING CESSATION AND BODY WEIGHT}

Quitting smoking has been shown to lead to an increase in body weight (Grunberg, 1982; Stamford et al. 1986) although this is not true of all smokers (Rodin, 1987). Changes in body weight and waist to hip ratio (WHR) from cessation studies are reviewed.

Table 6 shows a summary of some studies that recorded weight changes at different times after cessation. Rodin (1987) found that smokers who quit gained an average of $1.4 \mathrm{~kg}$ but that some lost weight. In those who gained, weight increased by $2.6 \mathrm{~kg}$ and in those who lost or maintained weight an average weight loss of $0.6 \mathrm{~kg}$ was found. Bosse et al. (1980), in a review article, looked at the relationship between smoking and weight gain over a 5 -year period in a large cohort of adult men. They found that $36 \%$ of quitters either lost weight or maintained the same weight after quitting. Characteristics prior to quitting smoking associated with weight gain after cessation were smoking cigarettes with a higher tar content, younger age and leanness of body build. Dallosso \& James (1984) found a mean weight gain of $1.36 \mathrm{~kg}$ in subjects who had quit for 6 weeks. They also showed a $4 \%$ drop in resting metabolic rate and an increase in energy intake of $6.5 \%$. Stamford et al. (1986) found a weight gain in women subjects who had quit for $48 \mathrm{~d}$ of $2.2 \mathrm{~kg}$, of which $96 \%$ was fat, $4 \%$ lean tissue and water. They found no change in resting metabolic rate over the $48 \mathrm{~d}$.

Williamson et al. (1991) related changes in body weight to changes in smoking habit in adults aged 25-74 years who were weighed between 1971 and 1975 and followed up between 1982 and 1984. Regardless of smoking status women tended to gain 1-2 kg more than men during the follow-up period. The mean weight gain attributable to the cessation of smoking (the difference between sustained quitters and continuing smokers) was $3.8 \mathrm{~kg}$ in women and $2.8 \mathrm{~kg}$ in men. Weight of quitters increased and was comparable to that of non-smokers at the follow-up appointment. Major weight gain ( $>13 \mathrm{~kg}$ ) occurred in $9.8 \%$ of men and $13.4 \%$ of women who quit smoking. The relative risk of major weight gain in quitters 
compared with smokers was 8.1 in men and 5.8 in women and it remained high regardless of the duration of cessation.

Weight gain appears to increase with time since quitting for up to one year, but may level out thereafter, perhaps suggesting that initial weight gain is followed by reduction and then reaches equilibrium.

Longitudinal associations between changes in smoking habits and changes in WHR have been examined (Shimokata et al. 1989). In men who started to smoke WHR increased and body mass index (BMI) fell but conversely on quitting BMI rose and WHR fell. It seems that smoking may have an influence on the pattern of distribution of body fat.

\section{SMOKING CESSATION AND NUTRIENT INTAKES}

\section{Macronutrient intakes}

Stamford et al. (1986) found an increase of $227 \mathrm{kcal}$ per day from $1765 \mathrm{kcal}$ in the baseline period to $1992 \mathrm{kcal}$ per day after cessation. During the baseline period, the average \% energy derived from protein, carbohydrate, fat and alcohol were 16, 43, 41 and $3 \cdot 4 \%$ respectively. During cessation, the percentages were $15,44,41$ and $2 \cdot 7 \%$ for $\%$ energy derived from protein, carbohydrates, fat and alcohol respectively. The constituents did not change even though the subjects reported a perceived increase in the consumption of sweets. Stubbe et al. (1982) also showed increased energy and fat intake. Rodin (1987) showed that quitters who maintained weight or lost weight reduced energy intake, but weight gain was associated with decreased protein and increased carbohydrate consumption following smoking cessation. Hall et al. (1989) found that energy, fat and sucrose intakes increased after the quit date. For abstinent subjects mean energy intake at 26 weeks was lower than that at baseline even though abstainers had gained $4 \cdot 1 \mathrm{~kg}$ in weight.

Small studies with close monitoring of diet may affect the subjects' eating patterns leading to lower weight gains and therefore these data may not be representative of the pattern in the general population.

There are some changes in macronutrient intakes after giving up smoking: there is an increase in energy intake in some quitters whilst others reduce energy intake. The excess energy consumed appears to come from fat and carbohydrate and may be due to extra snacks between meals. Weight gain immediately after cessation may result in lower energy intakes to reduce the excess weight gained.

\section{Micronutrient intakes}

Micronutrient intakes differ between smoking categories in observational studies, so it might be expected that on quitting smoking micronutrient intakes would rise. In these short term cessation studies only Rodin (1987) measured micronutrient intakes, but found no changes in the intake of vitamin A, ascorbic acid, thiamin, or iron after cessation. Further work is required to assess change in nutrient intakes upon stopping smoking.

Other potential causes of weight gain

Dietary changes do not seem to account for the increase in weight or differences between non-smokers and smokers. It is possible that smoking decreases nutrient absorption or increases metabolic rate. Hofstetter et al. (1986) found an increased energy expenditure in smokers after $24 \mathrm{~h}$ in a metabolic chamber but no changes in physical activity or mean basal metabolic rate. Perkins et al. (1990) showed that smoking had no greater effect on metabolic rate than meal consumption. Robinson \& York (1988) found a greater magnitude of diet induced thermogenesis in smokers who were allowed to smoke than in 
non-smokers after a $12-\mathrm{h}$ abstention from smoking. Therefore, it is possible that smoking increases energy expenditure in the short term and regular smoking leads to a larger energy expenditure which declines when smoking ceases. However, these effects are small and the extent to which they could influence body weight is not clear and needs closer examination.

There appear to be changes in weight and dietary habits (although much of the work has concentrated on energy intakes) on smoking cessation. Weight gain appears partly as a result of increases in energy intake immediately on quitting, but further work needs to be carried out to find other possible causes. More information is necessary from smokers as they quit to see if all smokers change their diet on quitting or whether large differences in a select group of smokers account for overall differences in the sample mean.

\section{RELATIONSHIPS BETWEEN NUTRIENT INTAKE AND CIGARETTE SMOKING AND CORONARY HEART DISEASE RISK FACTORS}

The possible relationships between nutrient intake, cigarette smoking and coronary heart disease are discussed. These include differences in anthropometry and lipid profile by smoking category and other risk factors such as blood pressure, and serum levels of fibrinogen, albumin and vitamins.

\section{ANTHROPOMETRY}

Mean BMI has been shown to be lower in male smokers compared with non-smokers (Fehily et al. 1984; Gregory et al. 1990; Cade \& Margetts, 1991; Troisi et al. 1991 for former smokers only). When subjects were divided into light, moderate and heavy smokers Fehily et al. (1984) showed that moderate smokers weighed the least with light smokers weighing more than heavy smokers $\left(25.8,25.3,25.6 \mathrm{~kg} / \mathrm{m}^{2}\right.$ for light to heavy smokers). Similar results were shown by Gregory et al. (1990), $25 \cdot 2,24 \cdot 2$ and $24 \cdot 6 \mathrm{~kg} / \mathrm{m}^{2}$ for nonsmokers, those smoking less than twenty cigarettes daily and those smoking more than twenty.

Larkin et al. (1990), using self-reported body weights, found that in women aged between 41 and 50 years smokers weighed less than never smokers but had similar weights to exsmokers. Within smoking categories moderate smokers were the lightest and light smokers the heaviest as found in men $(67 \cdot 6,62 \cdot 8,65 \cdot 7 \mathrm{~kg}$ in those women who smoked 1-10, 11-20 and more than 20 cigarettes per day respectively). Also, in women, Cade \& Margetts (1991) but not Gregory et al. (1990) found a lower BMI in smokers compared with non-smokers ( 26.2 non-smokers and ex-smokers and $24.9 \mathrm{~kg} / \mathrm{m}^{2}$ smokers).

A recent study of 17-year-old adolescent smokers showed that regular smokers had a statistically significantly higher BMI than those who had never smoked regularly (Townsend et al. 1991).

Shimokata et al. (1989) found higher WHR in smokers compared with non-smokers. A graded dose-response relationship was found between the number of cigarettes smoked and WHR.

The possible relation between obesity and cardiovascular disease has been the subject of great controversy. BMI is generally the term used for defining obesity and a level of 30 $\mathrm{kg} / \mathrm{m}^{2}$ or greater is considered to refer to obesity. In a cohort of Swedish men and women baseline measures of obesity were compared with incidence of heart disease during a 13year follow-up period. Larsson et al. (1984) found WHR but not BMI was predictive of ischaemic heart disease in men, but when smoking, systolic blood pressure and serum cholesterol were taken into account the relationship was not statistically significant. 
Lapidus et al. (1984) showed in women both WHR and to a lesser extent BMI were positively associated with coronary disease and that the relationship was independent of smoking, blood pressure, and age. Manson et al. (1990) also found that after controlling for smoking a BMI of $23 \mathrm{~kg} / \mathrm{m}^{2}$ or more was associated with an increased risk of heart disease in middle-aged women. They also showed that current smokers who were obese had an excess risk of heart disease. The relationship between body weight or adiposity and smoking is further confounded by alcohol consumption. Alcohol consumers generally weigh less than non-drinkers at similar or higher energy intakes (Hellerstedt et al. 1990).

Smokers, despite having a lower BMI than non-smokers, have increased WHR, which may be a better predictor of coronary disease. However, the relationship between diet, smoking and coronary heart disease is complicated by associations between diet, alcohol and BMI. Although smokers tend to consume more alcohol and have a different distribution of body fat, the extent to which this is independent of dietary intake in influencing risk of coronary heart disease is not clear.

\section{LIPIDS}

Blood lipid and lipoprotein concentrations have been measured in smokers and nonsmokers. Craig et al. (1989) collated information from fifty-four published studies and showed that smokers had significantly higher serum concentrations of cholesterol $(3 \%)$, triglycerides $(9 \cdot 1 \%)$, low-density lipoprotein (LDL) cholesterol $(1.7 \%)$ and significantly lower serum levels of high-density lipoprotein cholesterol (HDLchol) (5.7\%) compared with non-smokers. This gives smokers a more atherogenic lipid profile than non-smokers. Muscat et al. (1991) found a dose-response relationship between the number of cigarettes smoked per day and increasing levels of plasma cholesterol. In men aged between 18 and 60 years plasma cholesterol rose by $3.3 \mathrm{mg} / 1$ per cigarette smoked daily; in women aged 31-50 years the rise was $4.8 \mathrm{mg} / 1$ per cigarette smoked per day. Acute smoking appears to increase the level of free fatty acids in the bloodstream by enhanced lipolysis (Kershbaum et al. 1966). This is probably mediated by catecholamines and may give rise to an increase in LDL concentration. The relationship between dietary cholesterol and fat intakes and serum cholesterol and lipopretein fractions is complex. Serum cholesterol is only weakly related to total fat intake, perhaps more so to saturated fat intake. Evidence from dietary surveys does not suggest that smokers consume substantially more saturated fat than nonsmokers and therefore the elevated serum cholesterol found in smokers may be due more to altered lipid metabolism rather than differences in dietary fat intake.

Lipid measurements have been carried out prospectively in smoking cessation studies. Quitting smoking has been associated with a rise in HDLchol (Stubbe et al 1982; Stamford et al. 1986; Feher et al 1990). Stubbe et al. (1982) showed that the rise in HDLchol was correlated with an increase in fat consumption. Quensel et al. (1989) maintained subjects on a constant diet whilst quitting and found no subsequent rise in HDLchol. Hence it appears that the rise in HDLchol is related to dietary changes which occur upon cessation of smoking.

\section{OTHER RISK FACTORS}

Hypertension is another risk factor for coronary heart disease. Cook et al. (1986) found higher blood pressures in male ex-smokers compared with current or never smokers, but Friedman et al. (1979) showed that systolic blood pressure was lower in male never smokers and female quitters than in current smokers. Gregory et al. (1990) found that mean systolic pressure for men was significantly higher for smokers of twenty of more cigarettes daily compared with non-smokers but there were no differences for women. For women, but not 
men, diastolic pressure was higher for those smoking twenty or more cigarettes daily compared with non-smokers and light smokers.

Raised plasma fibrinogen is a recognized independent risk factor for coronary heart disease. The Northwick Park Heart Study demonstrated an association between high plasma fibrinogen levels and risk of ischaemic heart disease (Meade et al. 1987). In addition cross-sectional data suggest that smokers on average have higher plasma fibrinogen levels than never smokers and ex-smokers. Data from ex-smokers showed that although fibrinogen levels appeared to fall quite soon after quitting it may take five years or more to reach levels of non-smokers. Follow-up of those who had quit 6 years ago showed a reduction in plasma fibrinogen of $4 \cdot 1 \%$ compared with those who continued to smoke over the 6 years. The effect of diet on fibrinogen levels needs further investigation.

A decreased serum albumin has been associated with an increase in mortality from cardiovascular disease (Phillips et al. 1989). Serum albumin levels are reduced in smokers compared with never and ex-smokers. How this may be related to diet is at present not clear. It is possible that cigarette smoking initiates an inflammatory response which may lead to both decreased albumin levels and increased plasma fibrinogen. These effects could be mediated by cytokines, which appear to be modulated by dietary components (Grimble, 1990).

Several other workers have looked at plasma vitamin status to see if this reflects the lower dietary intakes. Lower serum levels of ascorbic acid in smokers compared with nonsmokers have been documented (Kallner et al. 1981; Smith \& Hodges, 1987; Duthie et al. 1989; Bridges et al. 1990; Riemersma et al. 1991). Smith \& Hodges (1987) showed that nearly three times as many cigarette smokers (not taking supplements) had a serum ascorbic acid of $\leqslant 0.03 \mathrm{mg} / \mathrm{ml}$ (a level considered to be of marginal deficiency) compared with non-smokers consuming a diet of similar ascorbic acid content. They estimated that smokers would need to consume an additional $59 \mathrm{mg}$ of ascorbic acid daily to reach levels of non-smokers. Kallner $e t$ al. (1981) suggested a requirement of $140 \mathrm{mg}$ per day for male smokers and $100 \mathrm{mg}$ for male non-smokers. Therefore, these studies seem to show that smokers may in fact require more ascorbic acid than the lower amounts they are consuming in comparison with non-smokers. Lower plasma concentrations of $\beta$-carotene have been found in smokers compared with non-smokers (Stryker et al. 1988; Herbeth et al. 1990; Bridges et al. 1990; Gregory et al. 1990). Vitamin A levels have been shown to be negatively related to number of cigarettes smoked (Bridges et al. 1990). There is little evidence to suggest lower levels of vitamin $\mathrm{E}$ in smokers compared with non-smokers although Gregory et al. (1990) found vitamin $\mathrm{E}$ and tocopherol:cholesterol ratios higher in male and female non-smokers than in heavy smokers. Riemersma et al. (1991) found plasma concentrations of vitamins $\mathrm{C}, \mathrm{E}$ and carotene were significantly inversely related to risk of angina and that smoking was a confounding factor. After adjustment for smoking only vitamin $E$ and vitamin $C$ to a lesser extent were significant.

These studies are consistent with data from dietary studies and may also indicate an increased requirement for antioxidant vitamins in smokers. The extent to which dietary differences and increased rates of catabolism contribute to these differences needs to be determined.

Cigarette smoking itself may cause tissue damage and promote atherosclerosis. Cigarette smoke is a source of free radicals (Machlin \& Bendich, 1987). Regular smokers are therefore subject to a high load of free radicals which have been shown to cause tissue damage (Duthie et al. 1989). A balance between free radical production and level of antioxidants is necessary to protect cells. An overload of free radicals could lead to a chain of lipid peroxidation and tissue damage. This high free radical load and relatively low antioxidant status may result in an imbalance of free radical antioxidant production which 


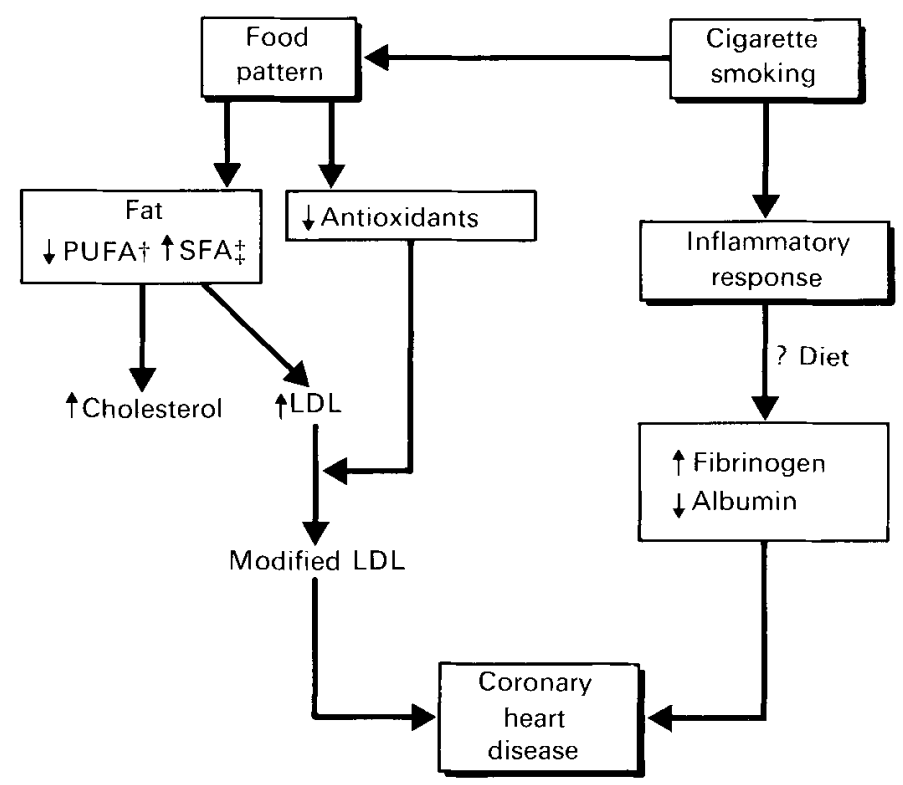

Fig. 1. Hypothesized relationships between smoking and diet which may lead to coronary heart disease. $\dagger$ Polyunsaturated fat. $\mp$ Saturated fat. LDL, Low-density lipoproteins.

may render lipoproteins more atherogenic (Duthie et al. 1989; Steinberg et al. 1989; Diplock, 1991; Luc \& Fruchart, 1991). There is some evidence to suggest that cigarette smoke is able to modify LDL and increase its atherogenicity. Yokode et al. (1988) showed that LDL pretreated with cigarette smoke stimulated $\left[{ }^{14} \mathrm{C}\right]$ cholesteryl oleate synthesis $12 \cdot 5$ fold compared with untreated LDL. Harats et al. (1989) and Scheffler et al. (1990) found twice the level of peroxidation from LDL of smokers than non-smokers. It is also possible that antioxidant supplements such as ascorbic acid and vitamin E may reduce levels of peroxidation in smokers (Harats et al. 1990).

In summary, smokers seem to have a more atherogenic lipid profile which may be affected as much by altered metabolic processes, such as increased catabolism of antioxidants, as by dietary differences.

\section{CONCLUSIONS AND FUTURE WORK}

Hypothesized relationships by which smokers increase their risk of coronary disease as a result of their dietary habits are shown in Fig. 1. Smoking cigarettes is associated with a different food pattern and altered nutrient intake, in particular more saturated fat, less polyunsaturated fat and lower consumption of antioxidant vitamins. These dietary changes may increase the risk of coronary disease by increased serum cholesterol and LDL concentrations. The increased free radical load from cigarette smoke, and the lower intakes of dietary antioxidants, may result in a free radical antioxidant imbalance which could lead to modification of LDL and atherogenesis. It is also possible that cigarette smoke initiates an inflammatory response associated with increased fibrinogen levels and decreased albumin concentrations. Much of the evidence is derived from cross-sectional studies of smokers and non-smokers and this limits the extent to which causal inferences can be drawn.

Experimental studies on small numbers of volunteers have been carried out looking at the effect of smoking cessation on body weight and dietary habits. However, there is a need 
for longer-term studies on representative samples of smokers who are followed as they stop smoking. This would then clarify whether cigarette smokers who quit change their diets, in what way and how quickly.

\section{REFERENCES}

Beynen, A. C., Hermus, R. J. J. \& Hautvast, J. G. A. J. (1980). A mathematical relationship between the fatty acid composition of the diet and that of adipose tissue in man. American Journal of Clinical Nutrition 33,81-85.

Bolton-Smith, C. \& Milne, A. C. (1991). Food frequency v. weighed intake data in Scottish men. Proceedings of the Nutrition Society 50, 35A.

Bolton-Smith, C., Woodward, M., Brown, C. A., Smith, W. C. S. \& Tunstall-Pedoe, H. (1991). Nutrient intakes from current, ex-and never smokers: results from the Scottish Heart Health Study. Proceedings of the Nutrition Society 50, 36A.

Bosse, R., Garvey, A. J. \& Costa, P. T. (1980). Predictors of weight change following smoking cessation. International Journal of Addictive Behaviour 15, 969-991.

Bridges, R. B., Chow, C. K.\& Rehm, S. R. (1990). Micronutrient status and immune function in smokers. Annals of the New York Academy of Sciences 587, 218-231.

Cade, J. E. \& Margetts, B. M. (1990). Smoking and diet: is the diet of smokers different? Proceedings of the Nutrition Society 49, $41 \mathrm{~A}$.

Cade, J. E. \& Margetts, B. M. (1991). The relationship between diet and smoking-is the diet of smokers different? Journal of Epidemiology and Community Health 45, 270-272.

Committee on Medical Aspects of Food Policy. Diet and cardiovascular disease (1984). Department of Health and Social Security Report on Health and Social Subjects no. 28. London: HMSO.

Cook, D. G., Shaper, A. G., Pocock, S. J. \& Kussick, S. J. (1986). Giving up smoking and the risk of heart attacks. Lancet ii, 1376-1380.

Craig, W. Y., Palomaki, G. E. \& Haddow, J. E. (1989). Cigarette smoking and serum lipid and lipoprotein concentrations: an analysis of published data. British Medical Journal 298, 784-788.

Dallosso, H. M. \& James, W. P. T. (1984). The role of smoking in the regulation of energy balance. International Journal of Obesity 8, 365-375.

Department of Health $(1991 \mathrm{a})$. On the State of the Public Health: the annual report of the chief medical officer of the Department of Health for the year 1990. London: HMSO.

Department of Health $(1991 b)$. Dietary reference values for food energy and nutrients for the United Kingdom. Report on Health and Social Subjects no. 41. London: HMSO.

Diplock, A. T. (1991). Antioxidant nutrients and disease prevention: an overview, American Journal of Clinical Nutrition 53, 189S-193S.

Doll, R. \& Peto, R. (1976). Mortality in relation to smoking; 20 years' observations on male British doctors. British Medical Journal ii, 1525-1536.

Duthie, G. G., Wahle, K. W. J. \& James, W. P. T. (1989). Oxidants, antioxidants and cardiovascular disease. Nutrition Research Reviews 2, 51-62.

Feher, M. D., Rampling, M. W., Brown, J., Robinson, R., Richmond, W., Cholerton, S., Bain, B. J. \& Sever, P. S. (1990). Acute changes in atherogenic and thrombogenic factors with cessation of smoking. Journal of the Royal Society of Medicine $\mathbf{8 3}, 146-148$.

Fehily, A. M., Phillips, K. M. \& Yarnell, J. W. G. (1984). Diet, smoking, social class, and body mass index in the Caerphilly Heart Disease Study. American Journal of Clinical Nutrition 40, 827-833.

Friedman, G. D., Siegelaub, A. B., Dales, L. G. \& Seltzer, C. C. (1979). Characteristics predictive of coronary heart disease in ex-smokers before they stopped smoking: comparison with persistent smokers and nonsmokers. Journal of Chronic Diseases 32, 175-190.

Fulton, M., Thomson, M., Elton, R. A., Brown, S., Wood, D. A. \& Oliver, M. F., (1988). Cigarette smoking, social class and nutrient intake: relevance to coronary heart disease. European Journal of Clinical Nutrition $\mathbf{4 2}$ 797-803.

Gregory, J., Foster, K., Tyler, H. \& Wiseman, M. (1990). The Dietary and Nutritional Survey of British Adults. London: HMSO.

Grimble, R. F. (1990). Nutrition and cytokine action. Nutrition Research Reviews 3, 193-210.

Grunberg, N. E. (1982). The effects of nicotine and cigarette smoking on food consumption and taste preferences. Addictive Behaviors 7, 317-331.

Hall, S. M., McGee, R., Tunstall, C., Duffy, J. \& Benowitz, N. (1989). Changes in food intake and activity after quitting smoking. Journal of Consulting and Clinical Psychology 57, 81-86.

Harats, D., Ben-Naim, M., Dabach, Y., Hollander, G., Stein, O. \& Stein, Y. (1989). Cigarette smoking renders LDL susceptible to peroxidative modification and enhanced metabolism by macrophages. Atherosclerosis 79 , 245-252.

Harats, D., Ben-Naim, M., Dabach, Y., Hollander, G., Havivi, E., Stein, O. \& Stein, Y. (1990). Effect of vitamin $\mathrm{C}$ and $\mathrm{E}$ supplementation on susceptibility of plasma lipoproteins to peroxidation induced by acute smoking. Atherosclerosis 85, 47-54. 
Haste, F. M., Brooke, O. G., Anderson, H. R., Bland, J. M., Shaw, A., Griffin, J. \& Peacock, J. L. (1990). Nutrient intakes during pregnancy: observations on the influence of smoking and social class. American Journal of Clinical Nutrition 51, 29-36.

Hellerstedt, W. L., Jeffery, R. W. \& Murray, D. M. (1990). The association between alcohol intake and adiposity in the general population. American Journal of Epidemiology 132, $594-611$

Herbeth, B., Chavance, M., Musse, N., Mejean, L. \& Vernhes, G. (1990). Determinants of plasma retinol, $\beta$-carotene and $\alpha$-tocopherol. American Journal of Epidemiology 132, 394-396.

Hofstetter, A., Schutz, Y., Jéquier, E. \& Wahren, J. (1986). Increased 24-hour energy expenditure in cigarette smokers. New England Journat of Medicine 314, 79-82.

Kallner, A. B., Hartmann, D. \& Hornig, D. H. (1981). On the requirements of ascorbic acid in men: steady state turnover and body pool in smokers. American Journal of Clinical Nutrition 34, 1347-1355.

Kershbaum, A., Bellet, S., Jimenez, J. \& Feinberg, L. J. (1966). Differences in effects of cigar and cigarette smoking on free fatty acid mobilization and catecholamine excretion. Journal of the American Medical Association 195, 1095-1098.

Klesges, R. C., Eck, L. H., Isbell, T. R., Fulliton, W. \& Hanson, C. L. (1990). Smoking status: effects on the dietary intake, physical activity, and body fat of adult men. American Journal of Clinical Nutrition 51, $784-789$.

Lapidus, L., Bengtsson, C., Larsson, B., Pennert, K., Rybo, E. \& Sjöström, L. (1984). Distribution of adipose tissue and risk of cardiovascular disease and death: a 12-year follow-up of participants in the population study of women in Gothenburg, Sweden. British Medical Journal 289, 1257-1261.

Larkin, F. A., Basiotis, P. P., Riddick, H. A., Sykes, K. E. \& Pao, E. M. (1990). Dietary patterns of women smokers and non-smokers. Journal of the American Dietetic Association 90, 230-236.

Larsson, B., Svärdsudd, K., Welin, L., Wilhelmsen, L., Björntorp, P. \& Tibblin, G. (1984). Abdominal adipose tissue distribution, obesity, and risk of cardiovascular disease and death: 13-year follow-up of participants in the study of men born in 1913. British Medical Journal 288, 1401-1404.

Lee, P. (1988). Misclassification of Smoking Habits and Passive Smoking. A Review of the Evidence. Berlin: Springer-Verlag.

Luc, G. \& Fruchart, J.-C. (1991). Oxidation of lipoproteins and atherosclerosis. American Journal of Clinical Nutrition 53, 206S-209S

Machlin, L. J. \& Bendich, A. (1987). Free radical tissue damage: protective role of antioxidant nutrients. $F A S E B$ Journal 1, 441-445.

Manson, J. E., Colditz, G. A., Stampfer, M. J., Willett, W. C., Rosner, B., Monson, R. R., Speizer, F. E. \& Hennekens, C. H. (1990). A prospective study of obesity and risk of coronary heart disease in women. New England Journal of Medicine 322, 882-889.

Meade, T. W., Imeson, J. \& Stirling, Y. (1987). Effects of changes in smoking and other characteristics on clotting factors and the risk of ischaemic heart disease. Lancet ii, 986-988.

Muscat, J. E., Harris, R. E., Haley, N. J. \& Wynder, E. L. (1991). Cigarette smoking and plasma cholesterol. American Heart Journal 121, 141-147.

National Advisory Committee on Nutrition Education (1983). Proposals for Nutritional Guidelines for Health Education in Britain. London: Health Education Council.

Perkins, K. A., Epstein, L H., Stiller, R. L., Sexton, J. E. Fernstrom, M. H., Jacob, R. G. \& Solberg, R. (1990). Metabolic effects of nicotine after consumption of a meal in smokers and non-smokers. American Journal of Clinical Nutrition 52, 228-233.

Phillips, A., Shaper, A. G. \& Whincup, P. H. (1989). Association between serum albumin and mortality from cardiovascular disease, cancer and other causes. Lancet ii, 1434-1436.

Quensel, M., Söderström, A., Agardh, C. D. \& Nilsson-Ehle, P. (1989). High-density lipoprotein concentrations afer cessation of smoking: the importance of alterations in diet. Atherosclerosis 75, 189-193.

Riemersma, R. A., Wood, D. A., MacIntyre, C. C. A., Elton, R. A., Gey, K. F. \& Oliver, M. F. (1991). Risk of angina pectoris and plasma concentrations of vitamins $\mathrm{A}, \mathrm{C}$, and $\mathrm{E}$ and carotene. Lancet 337, 1-5.

Robinson, S. M.\& York, D. A. (1988). Cigarette smoking and the thermic responses to isocaloric meals of varying composition and palatability. European Journal of Clinical Nutrition 42, 551-559.

Rodin, J. (1987). Weight change following smoking cessation: the role of food intake and exercise. Addictive Behaviors 12, 303-317.

Scheffler, E., Huber, L., Frühbis, J., Schulz, I., Ziegler, R. \& Alois Dresel, H. (1990). Alteration of plasma lowdensity lipoprotein from smokers. Atherosclerosis 82, 261-265.

Secretary of State for Health (1991). Health of the Nation. London: HMSO.

Shaper, A. G., Pocock, S. J., Walker, M., Phillips, A. N., Whitehead, T. P. \& MacFarlane, P. W. (1985). Risk factors for ischaemic heart disease: the prospective phase of the British Regional Heart Study. Journal of Epidemiology and Community Health 39, 197-209.

Shimokata, H., Muller, D. C. \& Andres R. (1989). Studies in the distribution of body fat. 3. Effects of cigarette smoking. Journal of the American Medical Association 261, 1169-1173.

Smith, J. \& Hodges, R. (1987). Serum levels of vitamin C in relation to dietary and supplemental intake of vitamin $\mathrm{C}$ in smokers and non-smokers. Annals of the New York Academy of Sciences 498, 144-151.

Stamford, B. A., Matter, S., Fell, R. D. \& Papanek, P. (1986). Effects of smoking cessation on weight gain, metabolic rate, caloric consumption, and blood lipids. American Journal of Clinical Nutrition 43, 486-494 
Steinberg, D., Parthasarathy, S., Carew, T. E., Khoo, J. C. \& Witztum, J. L. (1989). Beyond cholesterol. Modifications of low-density lipoprotein that increase its atherogenicity. New England Journal of Medicine 320, 915-924.

Strain, J. J., Thompson, K. A. \& Barker, M. E. (1991). Dietary intakes of smokers and non-smokers in the Northern Ireland population. Proceedings of the Nutrition Society 50, $101 \mathrm{~A}$.

Stryker, W. S., Kaplan, L. A., Stein, E. A., Stampfer, M. J., Sober, A. \& Willett, W. C. (1988). The relation of diet, cigarette smoking, and alcohol consumption to plasma beta-carotene and alpha-tocopherol levels. American Journal of Epidemiology 127, 283-296.

Stubbe. I., Eskilsson, J. \& Nilsson-Ehle, P. (1982). High-density lipoprotein concentrations increase after stopping smoking. British Medical Journal 284, 1511-1513.

Subar, A. F., Harlan, L. C. \& Mattson, M. E. (1990). Food and nutrient intake differences between smokers and non-smokers in the US. American Journal of Public Health 80, 1323-1329.

Sutton, S. R., Russell, M. A. H., Iyer, R., Feyerabend, C. \& Saloojee, Y. (1982). Relationship between cigarette yields, puffing patterns, and smoke intake: evidence for tar compensation? British Medical Journal 285, 600-606.

Townsend, J., Wilkes, H., Haines, A. \& Jarvis, M. (1991). Adolescent smokers seen in general practice: health, lifestyle, physical measurements, and response to antismoking advice. British Medical Journal 303, 947-950.

Troisi, R. J., Heinold, J. W., Vokonas, P. S. \& Weiss, S. T. (1991). Cigarette smoking, dietary intake, and physical activity: effects on body fat distribution - the Normative Aging Study. American Journal of Clinical Nutrition 53, $1104-1111$.

Whichelow, M. J. (1989). Choice of spread by a random sample of the British population. European Journal of Clinical Nutrition 43, 1-10.

Whichelow, M.J. \& Erzinglioglu, S. W. (1990). Comparison of the diets of smokers and non-smokers. Proceedings of the Nutrition Society 49, 42A.

Whichelow, M. J., Golding, J. F. \& Treasure, F. P. (1988). Comparison of some dietary habits of smokers and non-smokers. British Journal of Addiction 83, 295-304.

Williamson, D. F., Madans, J., Anda, R. F., Kleinman, J. C., Giovino, G. A. \& Byers, T. (1991). Smoking cessation and severity of weight gain in a national cohort. New England Journal of Medicine 324, 739-745.

Yokode, M., Kita, T., Arai, H., Kawai, C., Narumiya, S. \& Fujiwara, M. (1988). Cholesteryl ester accumulation in macrophages incubated with low-density lipoprotein pretreated with cigarette smoke extract. Proceedings of the National Academy of Sciences, USA 85, 2344-2348. 